\title{
ТЕОРИЯ ОРГАНИЗАЦИИ РАЦИОНАЛЬНОГО ЗЕМЛЕПОЛЬЗОВАНИЯ НА ОСНОВЕ ПОДХОДА К ИЗУЧЕНИЮ ЛОКАЛИЗАЦИИ СТОИМОСТИ НА ТЕРРИТОРИИ
}

\section{Татьяна Николаевна Жигулина}

Алтайский государственный аграрный университет, 656049, Россия, г. Барнаул, пр. Красноармейский, 98, кандидат экономических наук, доцент кафедры землеустройства, земельного и городского кадастра, e-mail: TNZhigulina@yandex.ru

\section{Валерий Александрович Мерецкий}

Алтайский государственный аграрный университет, 656049, Россия, г. Барнаул, пр. Красноармейский, 98, кандидат биологических наук, доцент кафедры землеустройства, земельного и городского кадастра, e-mail: kzg@asau.ru

В статье рассмотрена одна из основных проблем системы управления земельными ресурсами государства - проблема информационного обеспечения принятия решений. На примере построения геоинформационной модели локализации стоимости земли, показана возможность определения различных по ценности территорий на основе интегрального учета рыночных данных о ценах предложения (сделки) и статистических показателей, характеризующих развитость качества социального обеспечения населения, в части наличия минимальных условий для комфортности проживания. Для понимания относительной ценности той или иной точки на цифровой модели построено подобие ценового рельефа. С помощью построенной модели на территории региона однозначно можно выделить несколько категорий территорий, отличающихся по ценности. Рассмотрены факторы, поясняющие сложившиеся категории территорий в регионе. Набор таких моделей дает действенный инструмент, способный эффективно строить прогнозы использования и предлагать конкретные механизмы совершенствования политики в области управления земельно-имущественным комплексом региона, направленной на повышение его ценности.

Ключевые слова: территория, локализация стоимости, геоинформационная модель, подход, организация рационального землепользования

\section{THEORY OF RATIONAL LAND USE ORGANIZATION BASED ON THE STUDY OF COST LOCALIZATION ON THE TERRITORY}

\section{Tatyana N. Zhigulina}

Altai state agrarian University, 98, Krasnoarmeysky Ave., Barnaul, 656049, Russia, Ph. D., Associate Professor, Department of Land Management, Land and Urban Cadastre, e-mail: TNZhigulina@yandex.ru

\section{Valery A. Meretsky}

Altai state agrarian University, 98, Krasnoarmeysky Ave., Barnaul, 656049, Russia, Ph. D., Associate Professor, Department of Land Management, Land and Urban Cadastre, e-mail: kzg@asau.ru

The article deals with one of the main problems of the land resources management system of the state - the problem of information support for decision-making. On the example of the geoinformation model of value localization, the possibility of determining the various values of the territories of the integral accounting of market data on the prices of the offer (transaction) and statistical indicators characterizing the development of the quality of social security of the population, in terms of the presence of minimum conditions for the comfort of living. To understand the relative 
value of a particular point, a digital model is based on the similarity of the price relief. With the help of the constructed model, several categories of territories that differ in value can be clearly distinguished on the territory of the region. The factors explaining the existing categories of territories in the region are considered. A set of such models provides an effective tool that can effectively build forecasts of use and offer specific mechanisms for improving the policy in the field of land and property complex management in the region, aimed at increasing its value.

Keywords: territory, localization of value, geoinformation model, approach, organization of rational land use

\section{Введение}

Организация рационального использования земель является одной из стратегических целей любого государства. Механизмом запускающим этот процесс, а также регулирующим и контролирующим его выступает система государственного управления земельными ресурсами. Рациональность использования земель может быть измерена в различных аспектах: землеустроительном, хозяйственном, управленческом, социальном, экономическом, экологическом.

О.И. Лебедева отмечает, что «ограниченность земли абсолютна и превращается в относительную ограниченность только с эффективностью использования блага, с рациональным землепользованием» [1].

Общепринятый землеустроительный подход к пониманию сущности рационального использования земель и их охраны достаточно обстоятельно изложен в трудах С.Н. Волкова, В.П. Троицкого, М.А. Гендельмана, П.Ф. Лойко и других. Согласно этого подхода рациональное использование земли предполагает такое ее использование, которое отвечало бы совокупным интересам общества, собственников и пользователей земли, обеспечивало наиболее целесообразное и экономически выгодное извлечение полезных свойств земли в процессе производства, оптимальное взаимодействие с окружающей средой, охрану и воспроизводство земельных ресурсов. При этом рациональность выражается через систему взаимосвязанных показателей, отражающих эффективность хозяйствования в отношении отдельного землепользования.

С развитием рыночных отношений в Российской Федерации общепринятый землеустроительный подход к пониманию процесса организации рационального использования земель следует рассматривать сквозь призму рынка, поскольку вместе с показателями внутрихозяйственной эффективности использования земель понятие рациональности землепользования стало включать в себя и показатели востребованности на рынке. И, если продукция, как результат функционирования землепользования, обращается на продовольственных рынках, и выражает его хозяйственную эффективность, то рациональность землепользования, и как процесса, и как территории может быть выражена через категории рынка земли. 


\section{Методы и материаль}

В качестве базового метода настоящего исследования использован метод геоинформационного моделирования. Модель локализации стоимости территорий региона построена с использованием технологии TIN (Triangulation Irregular Network), которая позволяет строить поверхности по нерегулярно расположенным точкам.

\section{Результаты и их обсуждение}

Роль земли в системе общественного воспроизводства неоспорима. В процессе эволюции экономической системы, при переходе от одного типа цивилизации к другому, экономистами раскрывались все новые грани земли как экономического блага: как территории (фактор жизненного пространства), основного средства производства, объекта социально-экономических отношений. Осознание земли как одного из основных экономических благ произошло еще в трудах физиократов, однако те абсолютизировали роль земли, считая ее единственным «производительным ресурсом», а «земледельческий труд»- единственным источником общественного богатства. Позднее тезис о земледельческом труде как о единственном источнике общественного богатства был опровергнут в трудах А. Смита, Д. Рикардо, которые доказали, что богатство создается любым трудом, а в развитие представлений о земле как об одном из основных факторов производства разработали основы теории земельной ренты. Появление ренты объективно порождается возникновением экономических отношений по поводу землевладения и передачи земли в аренду (землепользования). В последствии принцип выявления земельной ренты был экстраполирован и на другие факторы, сформировав более широкое понятие экономической ренты.

С.Н. Ивашковский, объединяя современные представления экономической теории, выделяет четыре особенности земли как фактора производства: это природный фактор, который не может быть воспроизведен по желанию, она имеет неограниченный срок службы, недвижима, при использовании в сельском хозяйстве, при соблюдении принципов рационального использования, повышает свою производительность [2].

Основными механизмами функционирования рынка земли являются спрос и предложение. Именно взаимодействие этих механизмов препятствует образованию равновесной цены на землепользования, которые не соответствуют критериям востребованности таких объектов на рынке. Таким образом, понятие рациональности землепользования с точки зрения рынка земли расширяется еще и понятием востребованности таких объектов.

Критерии востребованности объекта, отчуждаемого на открытом рынке, косвенно (через последовательное отрицание субъектами сделки отдельных положений, вынуждающих их осуществлять такую сделку не по своей воле) прописаны в Федеральном законе №135-Ф3 «Об оценочной деятельности в Российской Федерации» от 29 июля 1998 года, а именно: 
- одна из сторон сделки не обязана отчуждать объект оценки, а другая сторона не обязана принимать;

- стороны сделки хорошо осведомлены о предмете сделки и действуют в своих интересах;

- объект оценки представлен на открытом рынке посредством публичной оферты, типичной для аналогичных объектов оценки;

- цена сделки представляет собой разумное вознаграждение за объект оценки и принуждения к совершению сделки в отношении сторон сделки с чьейлибо стороны не было;

- платеж за объект оценки выражен в денежной форме» [3].

Спецификой землепользований как товара, обращаемого на рынке земли, является их жесткая локализация на территории посредствам местоположения каждого землепользования.

Различия в условиях местоположений различных землепользований способствуют формированию на различных территориях локальных рынков земли и недвижимости. Каждый из таких локальных рынков выступает в виде механизма включенности экономического пространства в экономическую деятельность.

Стратегической целью системы управления земельными ресурсами региона является политика, направленная на повышение ценности его территорий. Понятие ценности территорий аграрного региона имеет несколько аспектов.

Первоочередным аспектом рассмотрения ценности территории является возможность ее эффективного использования как природного ресурса и основного средства производства в сельском хозяйстве. Такой аспект рассмотрения во многом объясняет закономерности возникновения и распространения по территории дифференциальной ренты I. На территории рассматриваемого региона данный аспект ценности территорий относится, в основном, к землям сельскохозяйственного назначения. Во втором случае ценность территорий региона может быть оценена с позиции эффективности исполнения ею функции товара и объекта социально-экономических отношений.

Поскольку территории сочетают в себе как производственные функции, так и функции жизнеобеспечения проживающего там населения, потенциальная ценность этой части экономического пространства должна складываться из сочетания двух аспектов ценности, описанных выше.

Именно это обстоятельство потребовало интегрального рассмотрения исходных данных при построении геоинформационной модели локализации стоимости территорий региона. Рассмотрим ее подробнее (рис. 1).

В основу построения модели положены данные о ценах предложения (сделках) с земельными участками, а также статистические показатели, характеризующие развитость качества социального обеспечения населения, в части наличия минимальных условий для комфортности проживания.

Для понимания относительной ценности той или иной точки на цифровой модели построили подобие ценового рельефа. Для этого территорию, изображенную 
в модели, разделили на отдельные области изолиниями (будем называть их изолиниями ценности) с величиной сечения 50 тыс. рублей/м2. Также для сравнения уровня ценности территорий приведены значения для городов и городских населенных пунктов (рис. 1).

С помощью построенной модели на территории региона однозначно можно выделить четыре категории территорий. Первая категория территорий - это крупные города краевого значения и территории, непосредственно составляющие с ними пригород.

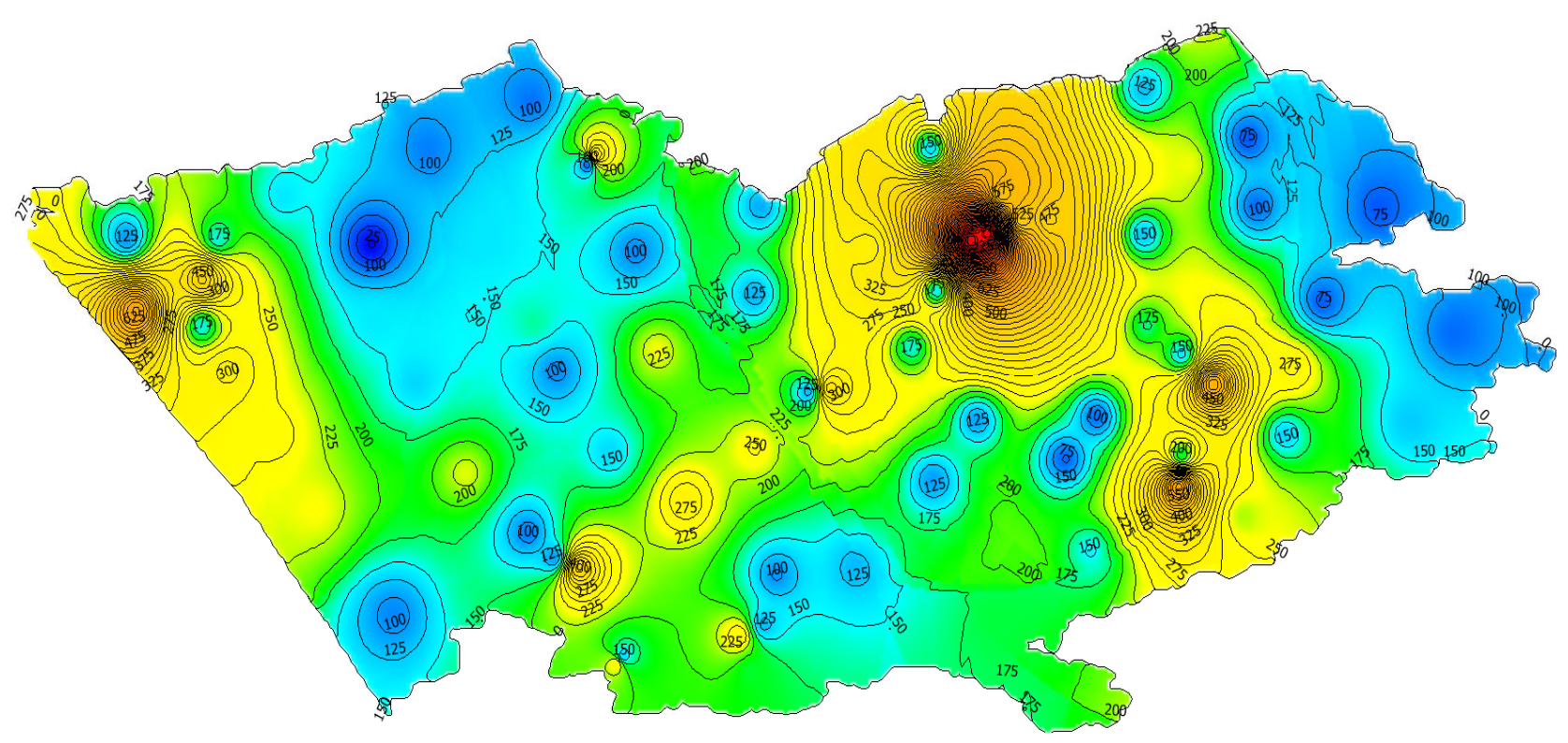

Диапазон средних удельных цен предложения земельных участков

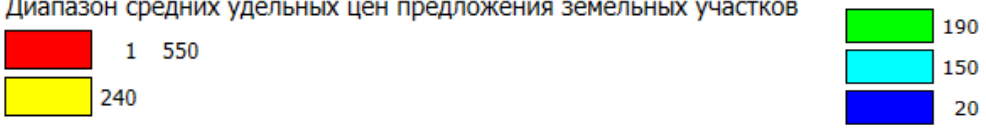

Ценовой рельеф

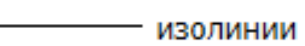

Рис. 1. Локализация стоимости земли на территории региона: распределение удельных цен предложения на земельные участки, руб/м²

Вторая категория территорий - это сельские территории Барнаульской агломерации, сельские территории, примыкающие к крупным городам первой категории территорий, а также отдельные территории муниципальных районов. Первые две категории территорий составляют в совокупности 30 \% территории региона.

Третья категория территорий представлена исключительно сельскими территориями муниципальных районов с включением крупных и мелких сельских населенных пунктов. Это основная часть модели - составляет 45 \% территорий региона.

Четвертая категория территорий - межселенные территории в муниципальных районах со слабым социально-экономическим развитием, а также мелкие сельские населенные пункты, что составляет 25 \% от изучаемой территории. 
Таким образом, большая часть сельских территорий исследуемого региона имеет пониженную ценность, а отдельные ее части можно и вовсе отнести к ареалам депрессивного развития (см. рис. 1, показаны темно-синим цветом).

Рассмотрим факторы, поясняющие сложившиеся категории территорий в регионе. По нашему мнению, это два основных фактора - социально-экономические выгоды от влияния крупных городов и наличия регулярного транспортного сообщения. Действие этих факторов наглядно продемонстрировано на рис. 2. Удаленность от крупного города показана с шагом 100 км.

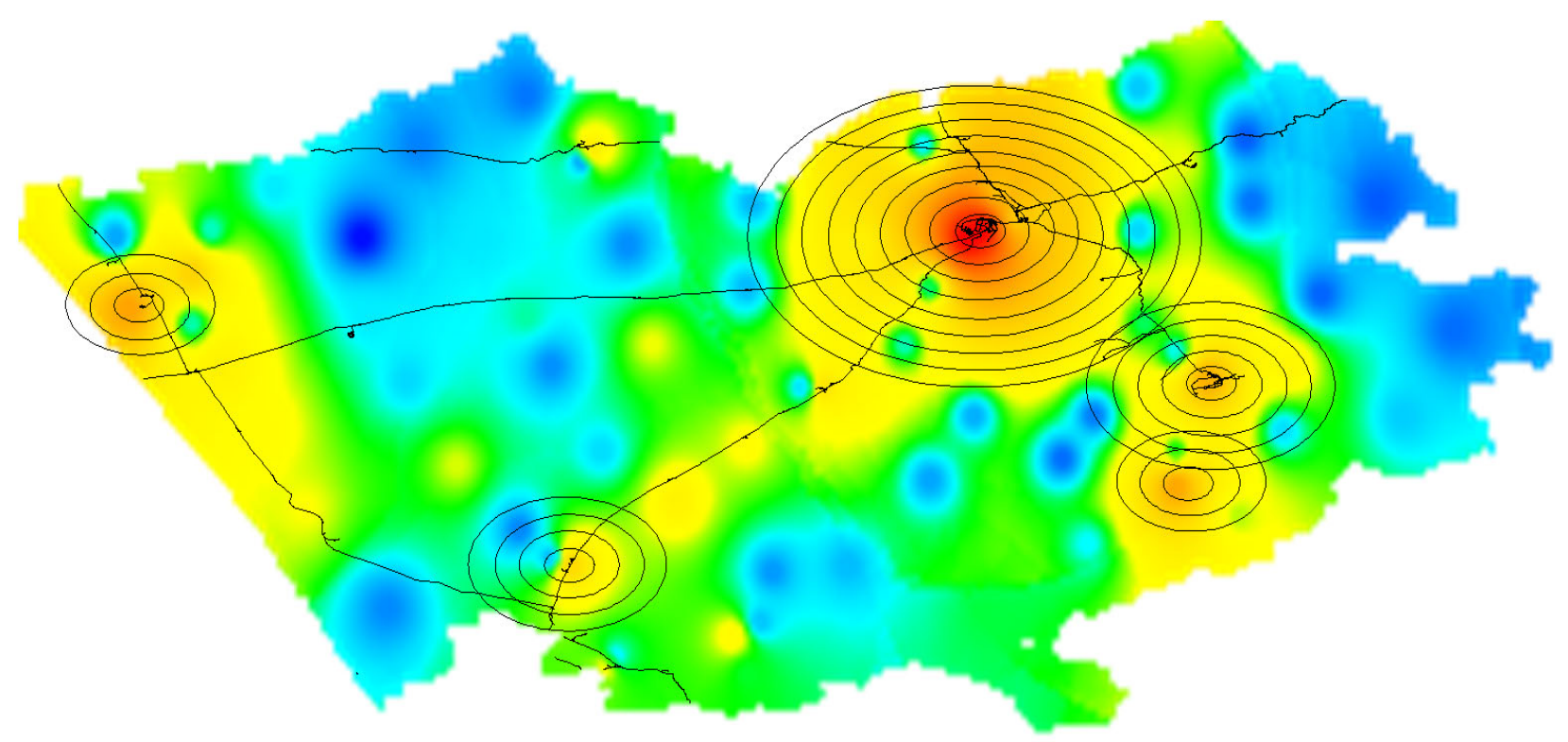

Рис. 2. Действие факторов: влияние крупных городов и наличия регулярного транспортного сообщения модель локализации стоимости земли (на примере Алтайского края)

С целью понимания природы формирования стоимости земли и иной недвижимости местоположение следует рассматривать не как географическую точку на карте, а сквозь призму пространственных понятий, характеризующих потребительские свойства землепользования путем изучения его принадлежности к определенной территории.

Основным из таких комплексных пространственных понятий, с помощью которого можно выразить относительную развитость и востребованность территории является экономическое устаревание. Геоинформационная модель экономического устаревания территорий построена нами на рис. 3.

Проводя сопряженный анализ геоинформационных моделей локализации стоимости земли и экономического устаревания территорий, следует отметить их тесную корреляционную связь: территории с наименьшим значением коэффициента экономического устаревания имеют наименьшую ценность на рынке. При этом их этого правила есть некоторые исключения. Так, в отношении ряда территорий, например, городов Ярового и Славгорода при среднем значении цен 
на земельные участки в диапазоне $700-250$ руб/м² величина экономического устаревания находится в одном из низших диапазонов $-0,7-0,5$. Это объяснимо тем, что на этих территориях нет развития активного инвестиционного процесса, а рыночная стоимость земли поддерживается исключительно за счет наличия уникальных природных ресурсов, активно вовлекаемых в туристические использование. В целом же эти территории депрессивные.

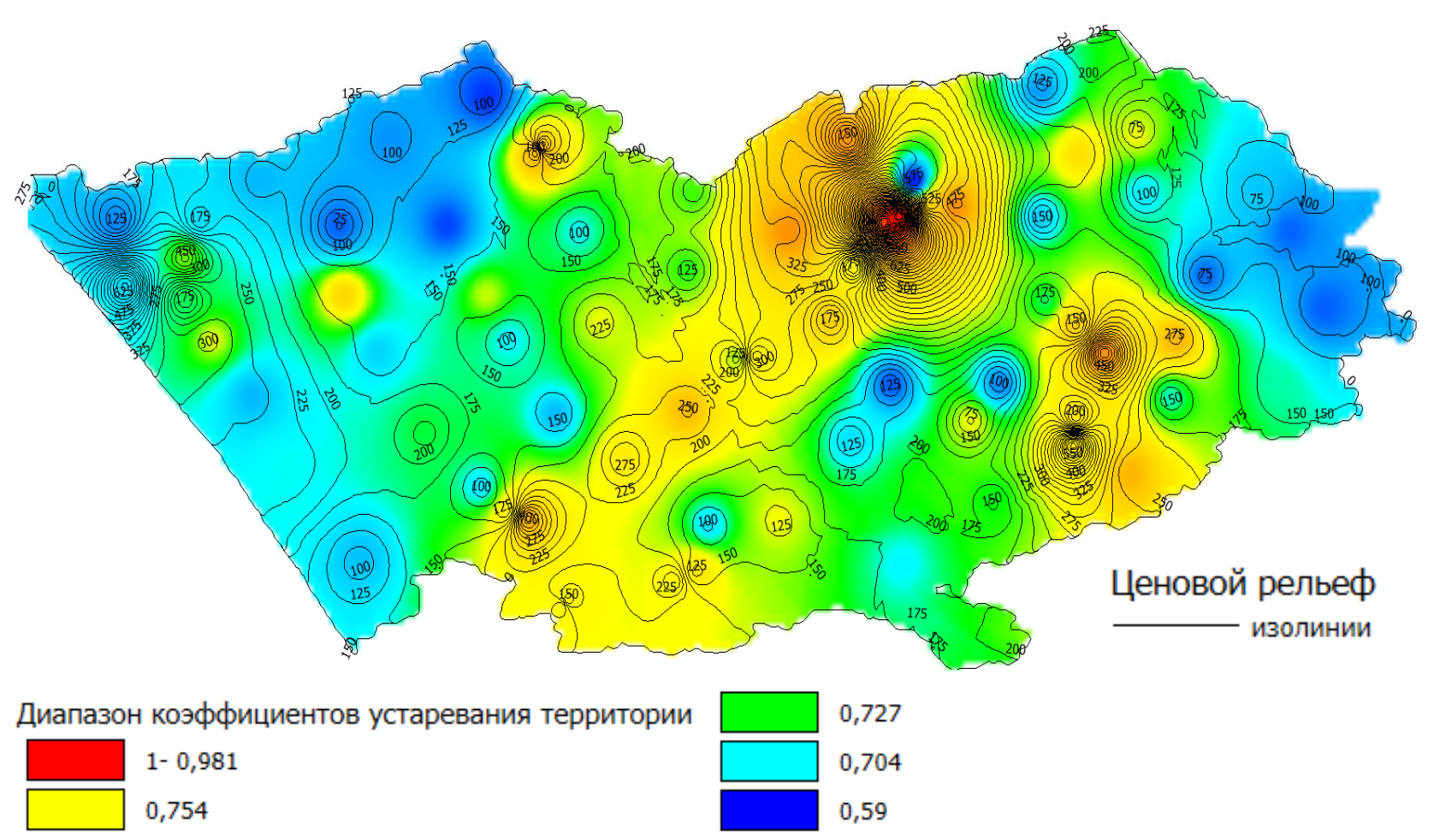

Рис. 3. Геоинформационная модель экономического устаревания территорий (на примере Алтайского края)

В настоящем исследовании, основываясь на выделенных категориях (типах) территорий дальнейшее развитие политики в области управления земельными ресурсами региона должно строиться по следующей схеме.

В отношении первой категории территорий должна вестись политика поддержания сложившегося уровня ценности, дальнейшее ее (ценности) увеличение возможно лишь за счет рыночных механизмов без активного государственного участия. На территориях второй категории поддержание и повышение ценности возможно путем привлечения дополнительных инвестиций, при этом требуется минимальное вложение в развитие инфраструктуры.

Третий и четвертый типы территорий депрессивные, поэтому требуют максимизации усилий государства по фактически их повторному включению в экономическое пространство региона и активный рыночный оборот. Депрессия связана как с развитием процессов агроистощения [4], так и недостаточностью предоставления социальных стандартов жизнеобеспечения, в этом случае необходима разработка целенаправленных программ стратегического развития 
депрессивных сельских территорий, направленных на восстановление утраченных функций по как производственных, так и функции жизнеобеспечения проживающего там населения.

\section{Заключение}

Таким образом, набор таких моделей дает действенный инструмент, способный эффективно строить прогнозы использования и предлагать конкретные механизмы совершенствования политики в области управления земельно-имущественным комплексом региона.

\section{БИБЛИОГРАФИЧЕСКИЙ СПИСОК}

1. Лебедева О. И. Проблемы оценки недвижимости в условиях рыночных товарно-денежных отношений // ПСЭ. 2010. №2.

2. Ивашковский С.Н. Микроэкономика: учеб. - 3-е изд., испр. - М.: Дело, 2002. -416 с.

3. Федеральный закон от 29 июля 1998 года «Об оценочной деятельности в Российской Федерации», №135-Ф3.

4. Meretsky V.A., Zhigulina T.N. Issue of agricultural lands exhaustion and land use planning and methodological approaches as solutions to this problem //IOP Conference Series: Earth and Environmental Science. 2020. C. 62041.

(C) T. Н. Жигулина, В. А. Мерецчкий, 2021 